PREPARED FOR THE U.S. DEPARTMENT OF ENERGY, UNDER CONTRACT DE-AC02-76CH03073

PPPL-3662

PPPL-3662

UC-70

High Heat Flux Interactions and Tritium Removal from Plasma Facing Components by a Scanning Laser

by

C.H. Skinner, C.A. Gentile, and A. Hassanein

January 2002

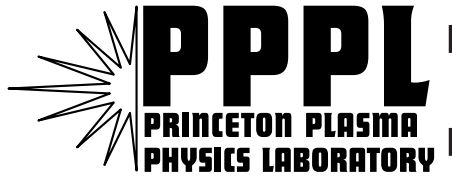

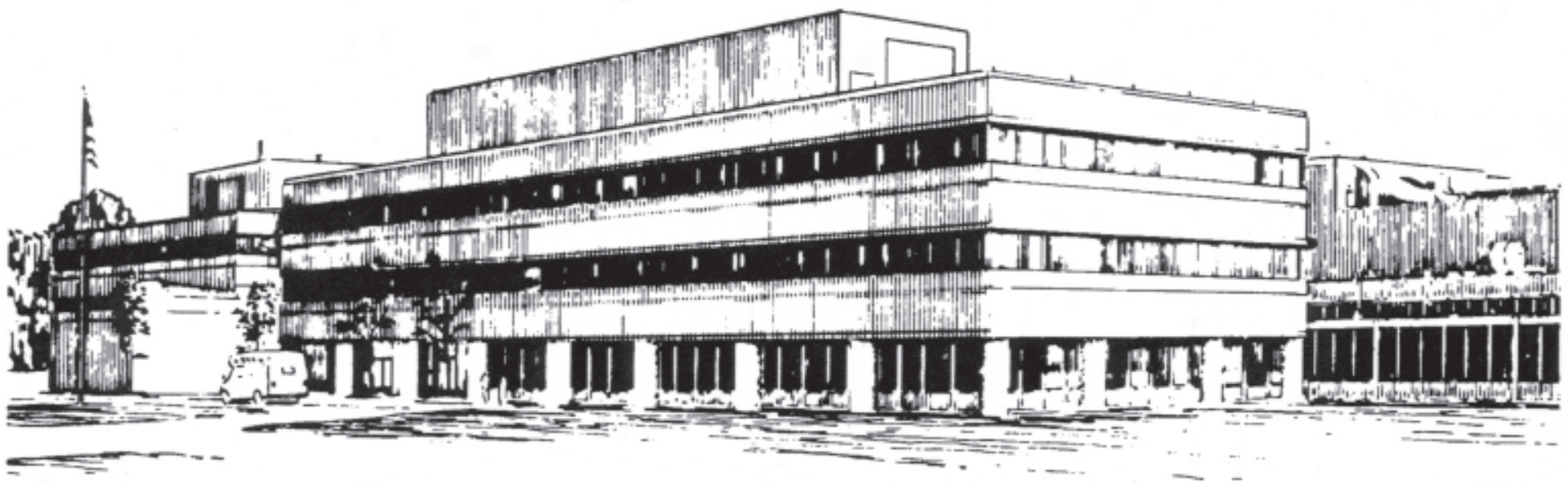

PRINCETON PLASMA PHYSICS LABORATORY PRINCETON UNIVERSITY, PRINCETON, NEW JERSEY 


\section{PPPL Reports Disclaimer}

This report was prepared as an account of work sponsored by an agency of the United States Government. Neither the United States Government nor any agency thereof, nor any of their employees, makes any warranty, express or implied, or assumes any legal liability or responsibility for the accuracy, completeness, or usefulness of any information, apparatus, product, or process disclosed, or represents that its use would not infringe privately owned rights. Reference herein to any specific commercial product, process, or service by trade name, trademark, manufacturer, or otherwise, does not necessarily constitute or imply its endorsement, recommendation, or favoring by the United States Government or any agency thereof. The views and opinions of authors expressed herein do not necessarily state or reflect those of the United States Government or any agency thereof.

\section{Availability}

This report is posted on the U.S. Department of Energy's Princeton Plasma Physics Laboratory Publications and Reports web site in Fiscal Year 2002. The home page for PPPL Reports and Publications is: http://www.pppl.gov/pub_report/

DOE and DOE Contractors can obtain copies of this report from:

U.S. Department of Energy

Office of Scientific and Technical Information

DOE Technical Information Services (DTIS)

P.O. Box 62

Oak Ridge, TN 37831

Telephone: (865) 576-8401

Fax: (865) 576-5728

Email: reports@adonis.osti.gov

This report is available to the general public from:

National Technical Information Service

U.S. Department of Commerce

5285 Port Royal Road

Springfield, VA 22161

Telephone: 1-800-553-6847 or

(703) 605-6000

Fax: (703) 321-8547

Internet: http://www.ntis.gov/ordering.htm 
Paper 125 r, 19th IEEE/NPSS Symposium on Fusion Engineering Atlantic City NJ, Jan $22^{\text {nd }}-25^{\text {th }} 2002$.

\title{
High Heat Flux Interactions and Tritium Removal from Plasma Facing Components by a Scanning Laser"
}

\author{
C. H. Skinner, C. A. Gentile and A. Hassanein ${ }^{\mathrm{a}}$. \\ Princeton Plasma Physics Laboratory, Princeton, New Jersey, 08543 \\ ${ }^{a}$ Argonne National Laboratory, Argonne, Illinois.
}

\begin{abstract}
A new technique for studying high heat flux interactions with plasma facing components is presented. The beam from a continuous wave $300 \mathrm{~W}$ neodymium laser was focussed to $80 \mathrm{~W} / \mathrm{mm}^{2}$ and scanned at high speed over the surface of carbon tiles. These tiles were previously used in the TFTR inner limiter and have a surface layer of amorphous hydrogenated carbon that was codeposited during plasma operations. Laser scanning released up to $84 \%$ of the codeposited tritium. The temperature rise of the codeposit on the tiles was significantly higher than that of the manufactured material. In one experiment, the codeposit surface temperature rose to 1,770 ${ }^{\circ} \mathrm{C}$ while for the same conditions, the manufactured surface increased to only $1,080{ }^{\circ} \mathrm{C}$. The peak temperature did not follow the usual square-root dependence on heat pulse duration. Durations of order $100 \mathrm{~ms}$ resulted in brittle destruction and material loss from the surface, while a duration of $\approx 10 \mathrm{~ms}$ showed minimal change. A digital microscope imaged the codeposit before, during and after the interaction with the laser and revealed hot spots on a 100 -micron scale. These results will be compared to analytic modeling and are relevant to the response of plasma facing components to disruptions and vertical displacement events (VDEs) in next-step magnetic fusion devices.
\end{abstract}

\section{INTRODUCTION}

$\mathrm{D}$ esigning a robust interface between a burning plasma and the material world remains a major issue for magnetic fusion[1]. The survival of plasma facing materials under ELMs, disruptions and vertical displacement events (VDEs), and the control of the tritium inventory are related challenges that must be met for magnetic fusion to achieve its promise as an attractive, environmentally acceptable energy source[2]. Carbon based materials have superior thermomechanical properties and do not melt (they sublime), however they cause high levels of tritium retention by codeposition with eroded carbon that would severely curtail plasma operations $[3,4]$ in a next-step device with carbon plasma facing components.

A novel technique to remove tritium from plasma facing components was proposed at the $17^{\text {th }}$ IEEE/NPSS Symposium for Fusion Engineering[5]. This takes advantage of advances in laser technology to rapidly heat co-deposited layers with a high-power scanning laser beam and thermally desorb tritium. Recent experimental tests have successfully removed $84 \%$ of the codeposited tritium on TFTR tiles by this method[6]. The technique is attractive for tritium removal in a next-step DT device since it avoids the use of oxidation, the associated deconditioning of the plasma facing surfaces and expense of processing large quantities of tritium oxide[7].

Under disruption conditions, next-step devices will experience heat loads more than two orders-of-magnitude higher than in present machines [2]. Comprehensive modeling codes[8] have been used simulate the conditions from the transport of the disrupting core plasma to the scrape-off-layer, the subsequent generation of a vapor shield at the divertor, and the reduced divertor plate lifetime due to melt layer loss and brittle destruction[9]. The thermo-mechanical response of graphite and carbon fiber composite (CFC) to very high heat flux includes sublimation, heating and explosion of gases trapped in the pores, and thermal stresses and fatigue. Pulsed lasers [10], electron beams [10] and plasma guns [11] have been used to reproduce some aspects of the interaction.

Surfaces of plasma facing components in tokamaks undergo ion bombardment and may accumulate deposits. The surface of tungsten is known to blister under high fluence ion bombardment $[12,13]$ and the surface thermal conductivity will change on a microscopic scale. Although designed for tritium removal, the present experiment offers an opportunity to study in microscopic detail the thermomechanical response of tokamak generated codeposits to high heat fluxes and pulse durations 10 - $300 \mathrm{~ms}$, in the range of disruptions and VDE's. The response is measured without the complications of vapor shielding, which may attenuate the thermal flux in a tokamak. The experimental setup is the same as used for the laser detritiation experiments fully reported in [6]. In the present paper we focus on the material response to the laser heat flux.

\section{EXPERIMENTAL SETUP}

A $300 \mathrm{~W}$ continuous wave $\mathrm{Nd}$ laser beam was typically focused to a $2 \mathrm{~mm}$ spot of $80 \mathrm{~W} / \mathrm{mm}^{2}$ intensity and scanned across a tile sample (Fig.1). The tiles were retrieved from TFTR after the tritium campaign and have tritiated codeposited layers of the order of 50 microns thick. The manufactured tile material was graphite (Union Carbide POCO AXF-5Q) and carbon fiber composite (Fiber Materials Inc. 4D coarse weave). The local duration of the heat pulse was varied from $10 \mathrm{~ms}$ to $300 \mathrm{~ms}$ by changing the scan speed. The change in surface temperature was recorded by an infra red pyrometer with $0.7 \mathrm{~mm}$ spatial and $0.3 \mathrm{~ms}$ temporal resolution. A digital microscope recorded the surface appearance before, during and after the laser exposure.
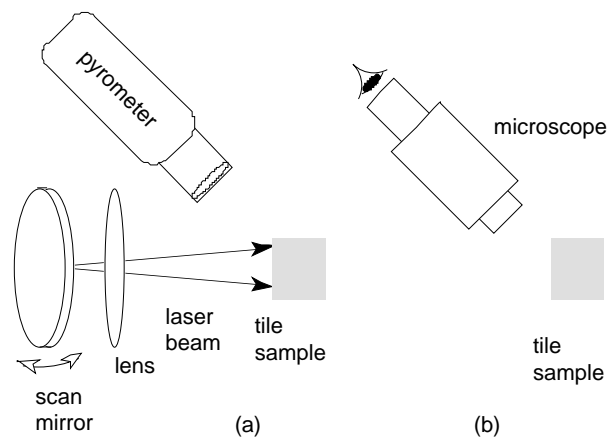

(b)

Fig. 1 Experimental setup for (a) laser scan and (b) microscopy.

\footnotetext{
*Work performed under US DOE Contracts: DE-AC02-76CH03073, and W-31-109-Eng-38.
} 


\section{TEMPERATURE RESPONSE}

A brilliant incandescent spot was generated by the focussed laser beam. In some cases the surface temperature rose to peak values over $2,300{ }^{\circ} \mathrm{C}$ (the pyrometer range is $500-2,300{ }^{\circ} \mathrm{C}$ ). The laser focus was scanned in a raster pattern and Fig. 2 shows the temperature response as a given position on the surface experienced first the fringe, then the center and then again the fringe of the laser spot. After irradiating the codeposited side, the sample was rotated to expose the manufactured graphite on the cut side with the same laser focal intensity and scan speed. As can be seen in Fig. 2, the maximum temperature rise of the codeposit, $1,770{ }^{\circ} \mathrm{C}$, was much higher than that of the manufactured tile material, 1,080 ${ }^{\circ} \mathrm{C}$. In a separate experiment, a CFC sample that exhibited both deposition and erosion areas, showed a peak temperature $1,841{ }^{\circ} \mathrm{C}$ on the deposition area compared to $1,181{ }^{\circ} \mathrm{C}$ on erosion area. The higher temperature is advantageous for tritium release. When the scan speed and hence local heating duration was varied, the peak temperature did not follow the expected square-root dependence on duration. Fig. 3 shows that the peak temperature increased by only $20 \%$ (from 1,682 to $2,02{ }^{\circ} \mathrm{C}$ ) after a $5 \mathrm{x}$ decrease in scan speed and corresponding increase in heating duration. Clearly additional heat absorption or surface removal mechanisms become active at longer durations. One can also see precursors in Fig. 3, most likely due to "burn-up" of loosely attached flakes and dust.

\section{MiCROSCOPY OF THE SURFACE}

A digital microscope recorded the surface appearance before and after the laser irradiation. Before laser irradiation, granulation and irregularities on the codeposited surface were readily apparent. After irradiation at high scan speeds $(1,000$ $\mathrm{mm} / \mathrm{s}$, surface temperature above $500{ }^{\circ} \mathrm{C}$ for $10 \mathrm{~ms}$ ) there is a slight color change but the codeposit appears undisturbed even though the temperature reached $1,770{ }^{\circ} \mathrm{C}$ and $18 \mathrm{mCi}$ of tritium was released (Fig. 4(a)) [6]. However, at slow scan speeds substantial surface damage and material loss from the surface occurs. Figs 4(c)-4(d) shows the results of a $25 \mathrm{~mm} / \mathrm{s}$ scan in which the laser irradiated a sequence of bands on the tile surface at increasing laser power.

Fig. 5 shows a microscope image of the surface during laser irradiation obtained by using the digital microscope in a video mode at 30 frames/s with $\times 100,000$ attenuation by a neutral density filter. The surface brightness shows discrete "micro hotspots" indicating that the temperature recorded in the 0.7 mm pyrometer viewing spot (Figs $2 \& 3$ ) averages over these features. It is clear that the surface granulation seen in Fig. 4 modulates the interaction. Granules that are poorly thermally connected to the underlying material will experience much higher temperatures than average. The range from threshold to saturated of an 8-bit CCD signal corresponds to a factor $\times 2$ to $\mathrm{x} 3$ temperature change so these are strong inhomegenities.

Fig. 5 shows clearly that microscopic structures are important in the temperature response of tokamak codeposits to plasma heat flux. An estimate of the temperature response using coefficients for bulk manufactured materials to see, for example, if the temperature rise remains below the threshold for radiation induced sublimation[14], may be unrealistic.

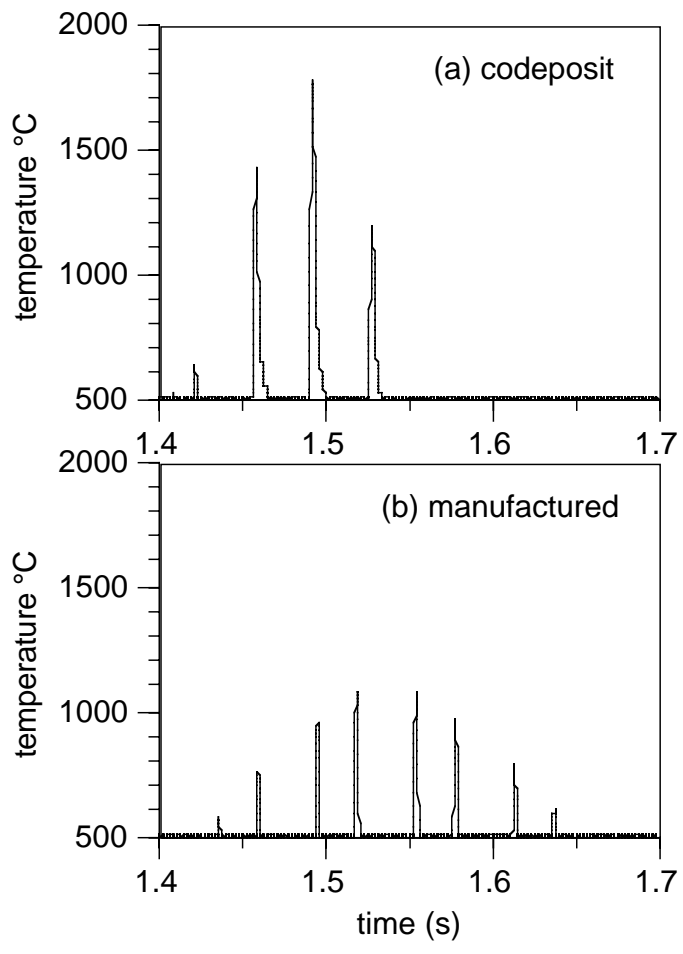

Fig. 2 Comparison of temperature response of (a) codeposit and (b) manufactured surface of graphite sample $\mathrm{KC} 226 \mathrm{E}$, both at a laser intensity of $80 \mathrm{~W} / \mathrm{mm}^{2}$, scan speed $1000 \mathrm{~mm} / \mathrm{s}$.

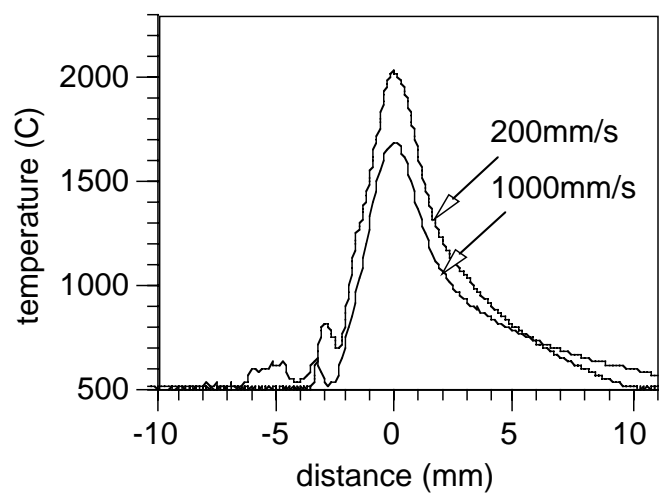

Fig. 3 Temperature response of CFC sample $\mathrm{KC} 17 \mathrm{1C}$ at scan speeds 200 and $1,000 \mathrm{~mm} / \mathrm{s}$. Laser intensity $80 \mathrm{~W} / \mathrm{mm}^{2}$ in both cases. The horizontal axis represents the distance between the pyrometer viewing spot and the scanning laser spot. Note that with $5 x$ longer heat pulse the peak temperature only increases $20 \%$.

\section{HEAT TRANSFER}

We first consider thermal conduction into the tile sample. Equation (1) describes the temperature, $\theta$, vs. depth, $x$, of a semi-infinite, homogeneous solid at zero initial temperature under a constant heat flux at $x=0$ beginning at $t=0[15]$ :

$$
\theta=\frac{2 F}{K}\left\{\left(\frac{\kappa t}{\pi}\right)^{1 / 2} \exp \left(\frac{-x^{2}}{4 \kappa t}\right)-\frac{x}{2} \operatorname{erfc} \frac{x}{2 \sqrt{\kappa t}}\right\}
$$

Here "erfc" is the complimentary error function, $K$ is the thermal conductivity, $\kappa=K / \rho c$ the thermal diffusivity. Note that in practice the carbon based materials are not homogeneous and the conductivity varies on a microscopic scale, is temperature dependent and the local laser intensity is 
not constant. Non the less Eqn. 1 predicts that a $10 \mathrm{~ms}, 80$ $\mathrm{W} / \mathrm{mm}^{2}$ heat flux will cause the surface of a graphite tile to rise from 500 to $1,104{ }^{\circ} \mathrm{C}$, similar to the measured temperature rise of 500 to $1,080^{\circ} \mathrm{C}$. The coefficients used are density: 2.1 $\mathrm{g} / \mathrm{cm}^{3}[16]$; thermal conductivity: $0.56 \mathrm{~W} / \mathrm{cm}-\mathrm{K}$ [17]; and heat capacity: $1.9 \mathrm{~J} / \mathrm{g}-\mathrm{K}[17]$; the latter two at 1,$000 ; \mathrm{C}$. Codeposits are known to have a more porous structure[18] and we make an ad hoc reduction by $50 \%$ of the density and thermal conductivity. For this case, Eqn. 1 predicts a temperature rise from 500 to $1,708{ }^{\circ} \mathrm{C}$ for the same heat pulse, similar to the measured temperature rise of the codeposit of 500 to $1,770{ }^{\circ} \mathrm{C}$. Fig. 6 shows the temperature response for the two cases. It is clear that predictions of surface temperatures of codeposited layers using thermal coefficients measured for manufactured materials may greatly underestimate the temperature rise of a codeposited layer.

The above analysis is approximate and, as evidenced by Fig. 5, the temperature will be strongly modulated by micro inhomogeneties. However it indicates that for the laser conditions found optimal for detritiation $\left(80 \mathrm{~W} / \mathrm{mm}^{2}, 10 \mathrm{~ms}\right.$ duration) thermal conduction will heat a 50 -micron thick codeposited layer to $\approx 1,500{ }^{\circ} \mathrm{C}$. Significantly higher intensities will cause the surface temperature to exceed the sublimation threshold $\left(2,600{ }^{\circ} \mathrm{C}\right)$ and longer durations will cause the heat to penetrate past the codeposited layer, both causing surface ablation and pore gas explosion that limit the peak temperature.

Another potential energy sink is the endothermic steam reaction[19]

$$
\mathrm{CO}+\mathrm{H}_{2} \mathrm{O}->\mathrm{CO}_{2}+\mathrm{H}_{2} \text {. }
$$

Oxides at an atomic concentration $20-50 \%$ have been detected in the codeposited surfaces of tiles retrieved from TFTR, presumably from moisture absorbed while in storage[20]. This reaction of interest as it is a potential source of hydrogen in a loss of coolant accident in a next-step device. More work is needed to ascertain its role in the present experiment.

\section{EROSION MECHANISMS OF CARBON-BASED-MATERIALS}

Nonmelting materials such as graphite and carbon based materials (CBMs) have shown large erosion losses in disruption simulation facilities that use electron beams [21], laser [22], plasma guns and other high-power devices [23]. The losses significantly exceed that from surface vaporization. Models have been developed and implemented in the HEIGHTS package[26] to evaluate erosion behavior and the lifetime of carbon based plasma facing and nearby components due to brittle destruction during plasma instabilities [24].

The macroscopic erosion of CBMs depends on the net power flux to the surface, exposure time, and threshold energy required for brittle destruction. This threshold is currently estimated from disruption-simulation experiments and is critical in determining the net erosion rate of CBMs. For MPG-9 graphite it is estimated to be $\approx 10 \mathrm{~kJ} / \mathrm{g}$, or $20 \mathrm{~kJ} / \mathrm{cm}^{3}$ [23]. Eqn. 1, with density and conductivity coefficients reduced to $50 \%$ of graphite values, predicts that a heat flux of $80 \mathrm{~W} / \mathrm{mm}^{2}$ for $10 \mathrm{~ms}$ or $0.8 \mathrm{~J} / \mathrm{mm}^{2}$ would result in a surface
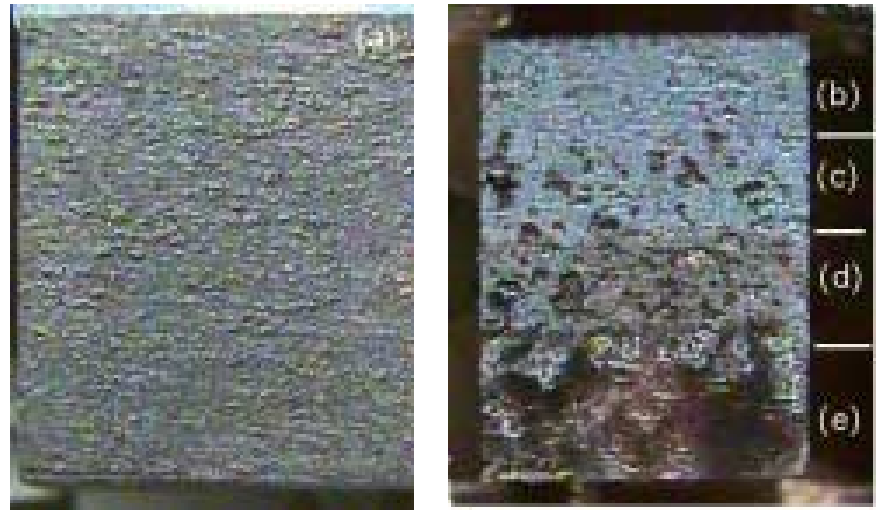

Fig. 4 (a) Codeposit on graphite sample $\mathrm{KC} 22-6 \mathrm{E}$ after irradiation at $80 \mathrm{~W} / \mathrm{mm}^{2}$, scan speed $1000 \mathrm{~mm} / \mathrm{s}$. This resulted in a $10 \mathrm{~ms}$ temperature excursion to $1,770{ }^{\circ} \mathrm{C}$ and the release of $18 \mathrm{mCi}$ of tritium; (b) original codeposit on CFC sample $\mathrm{KC} 17-3 \mathrm{C}$, and after 25 $\mathrm{mm} / \mathrm{s}$ irradiation at $9 \mathrm{~W} / \mathrm{mm}^{2}$ (c) $29 \mathrm{~W} / \mathrm{mm}^{2}$ (d), $77 \mathrm{~W} / \mathrm{mm}^{2}$ (e). For (e) the temperature excursion $>500{ }^{\circ} \mathrm{C}$ lasted $222 \mathrm{~ms}$ and peaked at $1,925^{\circ} \mathrm{C}$. The horizontal width of the samples are $24 \mathrm{~mm}$ and $15 \mathrm{~mm}$ respectively.

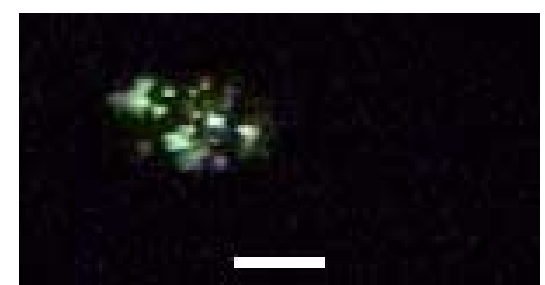

Fig. 5 Microscope image of laser interaction with sample KC17-2B at $80 \mathrm{~W} / \mathrm{mm}^{2}, 50 \mathrm{~mm} / \mathrm{s}$. The scale bar indicates $1 \mathrm{~mm}$.

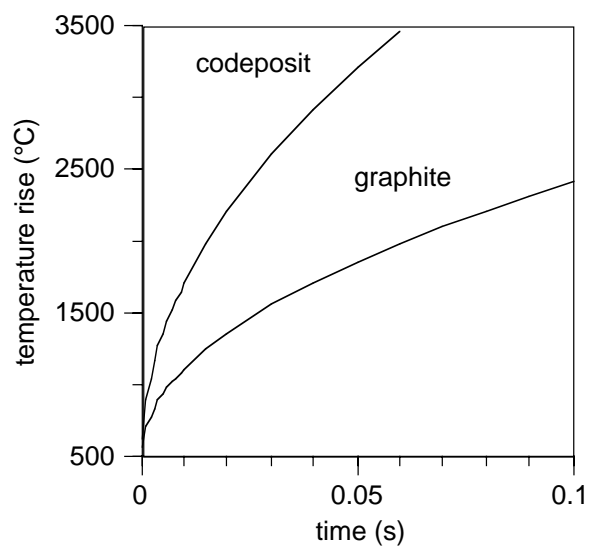

Fig. 6 Temperature rise of POCO AXF-5Q graphite and codeposit for $80 \mathrm{~W} / \mathrm{mm}^{2}$ (from Eqn. 1 -see text).

temperature of $1,000{ }^{\circ} \mathrm{C}$ at 300 microns below the surface. The $20 \mathrm{~kJ} / \mathrm{cm}^{3}$ brittle destruction threshold corresponds to 6 $\mathrm{J} / \mathrm{mm}^{2}$ if absorbed in a codeposited layer 300 microns thick. Thus, the experimental conditions for a $1000 \mathrm{~mm} / \mathrm{s}$ scan appear to be below the brittle destruction threshold, consistent with the minimal changes seen in Fig. 4(a). For a $100 \mathrm{~ms}$ duration heat pulse the surface temperature exceeds the sublimation threshold (Fig. 6) implying the onset of sublimation and pore gas explosion which is consistent with the surface damage observed in Fig. 4(e). 


\section{CONCLUSIONS}

The thermal response of deposition areas on graphite and CFC plasma facing components is significantly different to that of the manufactured material. The temperature rise is much higher and varies strongly on a 100-micron spatial scale. 1D heat flux calculations for plasma facing components typically use global values of thermal conductivity from manufactured materials to predict the surface temperature under a given heat load. A large influx of carbon during TFTR plasma operations was attributed to radiation induced sublimation, when temperatures of the plasma facing graphite limiter surface exceeded a threshold value of $1,650^{\circ} \mathrm{C}[25]$ so it is important that surface temperatures stay below this value during projected heat loads. The above results illustrate that the thermal response of codeposits is markedly different to the manufactured tile materials and has large microscopic spatial variations. Reliable predictions for the thermal behavior of deposition areas need to be based on experiments with tokamak-generated codeposits and relevant pulse durations. This issue also complicates measurements of heat flux at plasma facing surfaces by IR thermography.

Erosion losses from brittle destruction are much higher than that predicted from pure surface vaporization [26]. This could have serious implications during loss of plasma confinement and disruptions in future tokamak devices. Macroscopic erosion of CBMs due to the various mechanisms of brittle destruction depends strongly on the type of carbon material. The erosion lifetime of CBM components could be significantly shorter than the hundreds of disruptions currently assumed for ITER-like devices. More experimental data and additional detailed modeling are urgently needed.

Tungsten avoids tritium codeposition issues but melt layer loss during off normal events may limit the operational lifetime[1]. Blistering has been observed after high ion fluence ion bombardment [27,28] and this is expected to also change the surface thermal conductivity on microscopic scale. Future work will study $\mathrm{W}$ samples pre-exposed to high fluence ion bombardment.

\section{ACKNOWLEDGMENT}

We thank G. Federici, D. Cahill, R. Causey, A. A. Haasz, R. Reichle, J. Roth and K. Young for informative discussions. The work would not have been possible without the dedicated work of the tritium group and collaborators at PPPL.

\section{REFERENCES}

[1] G. Federici, V. Barabash, G. Janeschitz, R. Tivey, C. H. Skinner, W. R. Wampler, J. Roth "Selection of plasma facing materials in next-step devices" in this proceedings.

[2] G. Federici, C H Skinner et al., "Plasma-material Interactions in Current Tokamaks and their Implications for Next-step Fusion Reactors", Nucl. Fusion, vol. 41, p.1967-2118, Dec 2001.

[3] C.H. Skinner, C.A. Gentile, K.M. Young, J.P. Coad, J.T. Hogan, R.-D. Penzhorn, N. Bekris "Long term tritium trapping in TFTR and JET" Proceedings of the $28^{\text {th }}$ EPS Conference on Controlled Fusion and Plasma Physics, Madeira, Portugal, 18-22 $2^{\text {nd }}$ June, 2001 http://www.cfn.ist.utl.pt/EPS2001/fin/pdf/P4.080.pdf

[4] C H Skinner and G Federici "Tritium Issues in Next-step Devices" Proceedings of the International Conference on Advanced Diagnostics for Magnetic and Interial Fusion, Kluwer Academic/Plenum, New York (2002).
[5] C. H. Skinner, H. Kugel, D. Mueller, B. L. Doyle, and W. R. Wampler, "Tritium removal by $\mathrm{CO}_{2}$ laser heating" Proceedings of the 17th IEEE/NPSS Symposium on Fusion Engineering, San Diego, October 610, 1997, vol. 1, pp.321-324, IEEE, Piscataway, NJ, USA (1998)

[6] C. H. Skinner, C. A. Gentile, A. Carpe, G. Guttadora, S. Langish, K. M. Young, W. M. Shu, and H. Nakamura "Tritium removal from codeposits on carbon tiles by a scanning laser" J. Nucl. Mater. in press (2002).

[7] C.H. Skinner, C. A. Gentile, G. Guttadora, A. Carpe, S. Langish, K. M. Young, M. Nishi, W. Shu., "Tritium removal by laser heating and its application to tokamaks" Proceedings of the $6^{\text {th }}$ International Conference on Tritium Science and Technology, Tsukuba City, Ibaraki, Japan, Nov $11-16^{\text {th }}$ to be published in Fusion Science and Technology (2002)

[8] A. Hassanein and I. Konkashbaev, J. Nucl. Mater. vol. 273 pp. 326-333 (1999).

[9] M. I. Guseva et al., "Selfsputtering of beryllium and sputtering and erosion of C_C composite in the experiments on plasma disruption simulation" J. Nucl. Mater., vol. 220-222 pp. 957-960 (1995).

[10] J. G. van der Laan, H. Th. Klippel, G. J. Kraaij, R. C. L. van der Stad, J. Linke and M. Akiba, "Effects of short pulse high heat fluxes on carbon base plasma facing materials for ITER" J. Nucl. Mater., vol. 196-198, pp. 612-617 (1992).

[11] T Burtseva, A Hassanein, I Ovchinnikov and V Titov, "Study of brittle destruction and erosion mechanisms of carbon based materials during plasma instabilities". J. Nucl. Mater., vol. 290-293 pp. 1059-1063 (2001).

[12] W. Wang, J. Roth, S. Lindig, and C. H. Wu, "Blister formation of tunsgten due to ion bombardment” J. Nucl. Mater., vol. 299 pp.124-131 (2001).

[13] A. A. Haasz, M. Poon, and J. W. Davis, "The effect of ion damage on deuterium trapping on tungsten" J. Nucl. Mater., vol. 266-269 pp. 520525 (1999).

[14] W. Eckstein, V. Philipps, "Physical Sputtering and Radiation-Enhanced Sublimation" in Physical processes of the interaction of fusion plasma with solids, Ed. by W.O. Hofer, and J. Roth,, Academic Press, San Diego, (1996) pp. 93-133.

[15] H S Carslaw and J C Jaeger, Conduction of Heat in Solids, Oxford University Press, Oxford, 2nd ed. (1959) p.75.

[16] CRC Handbook of Chemistry and Physics.

[17] A W Brooks, FDR report, July 201992.

[18] B. E. Mills, D. A. Buchenauer, A. E. Pontau, M. Ulrickson, J. Nucl. Mater. "Characterization of deposition and erosion of the TFTR bmper limiter" pp.343-349 vol. 162-164 (1989).

[19] G. R. Smolik et al., "Evaluation of graphite/steam interactions for ITER", Idaho National Engineering Laboratory report, EGG-FSP-9154, September 1990.

[20] M T. Paffett and R. S. Willms, C. A. Gentile and C. H. Skinner "Surface Characterization of TFTR First Wall Graphite tiles used during DT operations" Fusion Science and Technology (2002) to be published.

[21] J. Linke et al., "Disruption simulation experiments in electron and laser beam facilities" in Fusion Technol., B. Keen, M. Huguet, and R. Hemsworth, eds., (1990) pp. 428-423.

[22] J. Van der Laan, "Effects of pulsed-laser radiation on first-wall materials" J. Nucl. Mater. 162-164 (1989) 964-969.

[23] A. V. Burdakov et al., "On the possibility of explosive material erosion under conditions of ITER disruption event" J. Nucl. Mater. 233-237 (1996) 697-700.

[24] A. Hassanein and I. Konkashbaev, "Physics of collisionless scrape-offlayer plasma during normal and off-normal tokamak operating conditions," Argonne National Laboratory Report ANL/FPP/TM-296, March 1999.

[25] A. T. Ramsey, C. E. Bush, H. F. Dylla, D. K. Owens, C. S. Pitcher and M. A. Ulrickson, "Enhanced carbon influx into TFTR supershots". Nucl. Fus. vol. 31 pp.1811-1825 (1991).

[26] A. Hassanein and I. Konkashbaev, "Lifetime evaluation of plasmafacing materials during a tokamak disruption.” J. Nucl. Mater 233-237 (1996) 713.

[27] W. M. Wang, J. Roth, S. Lindig, and C. H. Wu "Blister formation of tungsten due to ion bombardment” J. Nucl. Mater., vol. 299 (2), pp. 124131 Nov. 2001.

[28] A. A. Haasz, M. Poon, J. W. Davis, "The effect of ion damage on deuterium trapping in tungsten" J. Nucl. Mater., vol. 266-260 pp. 520525 (1999). 


\section{External Distribution}

Plasma Research Laboratory, Australian National University, Australia

Professor I.R. J ones, Flinders University, Australia

Professor J oão Canalle, Instituto de Fisica DEQ/IF - UERJ , Brazil

Mr. Gerson O. Ludwig, Instituto Nacional de Pesquisas, Brazil

Dr. P.H. Sakanaka, Instituto Fisica, Brazil

The Librarian, Culham Laboratory, England

Library, R61, Rutherford Appleton Laboratory, England

Mrs. S.A. Hutchinson, JET Library, England

Professor M.N. Bussac, Ecole Polytechnique, France

Librarian, Max-Planck-Institut für Plasmaphysik, Germany

J olan Moldvai, Reports Library, MTA KFKI-ATKI, Hungary

Dr. P. Kaw, Institute for Plasma Research, India

Ms. P.J . Pathak, Librarian, Insitute for Plasma Research, India

Ms. Clelia De Palo, Associazione EURATOM-ENEA, I taly

Dr. G. Grosso, Instituto di Fisica del Plasma, Italy

Librarian, Naka Fusion Research Establishment, J AERI, J apan

Library, Plasma Physics Laboratory, Kyoto University, J apan

Research Information Center, National Institute for Fusion Science, J apan

Dr. O. Mitarai, Kyushu Tokai University, J apan

Library, Academia Sinica, Institute of Plasma Physics, People's Republic of China

Shih-Tung Tsai, Institute of Physics, Chinese Academy of Sciences, People's Republic of China

Dr. S. Mirnov, TRINITI, Troitsk, Russian Federation, Russia

Dr. V.S. Strelkov, Kurchatov Institute, Russian Federation, Russia

Professor Peter Lukac, Katedra Fyziky Plazmy MFF UK, Mlynska dolina F-2, Komenskeho Univerzita, SK-842 15 Bratislava, Slovakia

Dr. G.S. Lee, Korea Basic Science Institute, South Korea

Mr. Dennis Bruggink, Fusion Library, University of Wisconsin, USA

Institute for Plasma Research, University of Maryland, USA

Librarian, Fusion Energy Division, Oak Ridge National Laboratory, USA

Librarian, Institute of Fusion Studies, University of Texas, USA

Librarian, Magnetic Fusion Program, Lawrence Livermore National Laboratory, USA

Library, General Atomics, USA

Plasma Physics Group, Fusion Energy Research Program, University of California at San Diego, USA

Plasma Physics Library, Columbia University, USA

Alkesh Punjabi, Center for Fusion Research and Training, Hampton University, USA

Dr. W.M. Stacey, Fusion Research Center, Georgia Institute of Technology, USA

Dr. J ohn Willis, U.S. Department of Energy, Office of Fusion Energy Sciences, USA

Mr. Paul H. Wright, Indianapolis, Indiana, USA 
The Princeton Plasma Physics Laboratory is operated by Princeton University under contract with the U.S. Department of Energy.

\author{
Information Services \\ Princeton Plasma Physics Laboratory \\ P.O. Box 451 \\ Princeton, NJ 08543
}

Phone: 609-243-2750

Fax: 609-243-2751

e-mail: pppl_info@pppl.gov

Internet Address: http://www.pppl.gov 